\title{
Estudo avaliativo da predisposição à síndrome de burnout em professores de uma Universidade de Parnaíba-PI
}

\author{
Evaluation on predisposition of professors to burnout syndrome at a university in \\ Parnaíba/Brasil
}

Estudio evaluativo de la predisposición al síndrome de burnout en profesores de una Universidad de Parnaíba-PI

Maria Fabiana Machado da Silva ${ }^{I}$

Lauriane Maria dos Santos Teles ${ }^{2}$

Savanna de Brito Ximenes Aragão ${ }^{3}$

Carla Fernanda de Lima Santiago da Silva ${ }^{4}$

Universidade Federal do Piaui - UFPI

\begin{abstract}
Resumo
Síndrome de burnout é um estresse ocupacional comum, principalmente, em profissionais atuantes em uma relação ininterrupta e emocional com outras pessoas (Tibúrcio \& Moreno, 2009). Avaliou-se sua predisposição em docentes de uma Universidade de Parnaíba-PI, utilizando-se do Maslach Burnout Inventory (MBI) e um questionário sociodemográfico. Para análise, empregou-se o software estatístico SPSS, versão 18.0, realizando-se análise de frequência dos dados sociodemográficos, Análise Fatorial (AF), que obteve três fatores: Exaustão, Realização Profissional, Despersonalização; Alpha de Cronbach 0,87; 0,79; 0,63, respectivamente, e média de cada dimensão para identificar a predisposição. Obtiveram-se baixos níveis de Exaustão e Despersonalização e altos de Realização Profissional; no entanto, em relação à frequência de pessoas, identificou-se um número significativo com índices médios de Exaustão, sugerindo alerta sobre a predisposição ao burnout.

Palavras-chave: Professores universitários; Exaustão; Síndrome de burnout.
\end{abstract}

\begin{abstract}
Burnout syndrome is a common occupational stress in general professional working with any sort of uninterruption and emotional relationship with others. Thus, we evaluated the predisposition of professors at a University of Parnaíba, in Parnaíba/ Brazil, to develop this syndrome by sociodemographic and professional/occupational questionnaires and Maslach Burnout Inventory (MBI). In that analysis, we used the statistical software SPSS, version 18.0, frequency analysis for sociodemographic and professional/occupational and factor analysis (FA), which had presented three factors: Exhaustion, Professional Achievement, Depersonalization - Cronbach's alpha $0.87,0.79$ and 0.63 , respectively, and the media of each dimension to identify predisposition. As conclusion, we obtained low levels of Exhaustion and Depersonalization and high levels of Professional Achievement, but we also found average rates of Exhaustion, this insinuated an alert about the predisposition of investigated to burnout syndrome.
\end{abstract}

Key-words: University professors; Exhaustion; Burnout syndrome.

\section{Resumen}

El síndrome de burnout es un esfuerzo común ocupacional en profesionales que trabajan de manera continua y emocional con los demás (Tiburcio y Moreno, 2009). Se ha evaluado su predisposición en una Universidad de Parnaíba-PI, mediante cuestionario sociodemográfico y Maslach Burnout Inventory (MBI). Para el análisis se utilizó del paquete SPSS, versión 18,0, y el análisis de frecuencias de los datos sociodemográfico y análisis factorial, (FA), del cual se ha obtenido tres factores: Agotamiento, Despersonalización y Logro profesional; alfa de Cronbach 0,87, 0,79 y 0,63 , respectivamente, y la media de cada dimensión para determinar la predisposición al agotamiento. Se ha obtenido niveles bajos de Agotamiento y Despersonalización y alto de Logro profesional, pero como en las frecuencias se han encontrado tasas medias de Agotamiento, lo que sugiere una disposición de los profesionales encuestados al síndrome de burnout.

Palabras-clave: Docentes de la universidad; Agotamiento; Síndrome de burnout.

\section{Introdução}

Endereço 1: Rua Zezita Sampaio, 62, Buriti dos Lopes-PI; CEP: 64.230-000; Buriti dos Lopes, Piaú.

Endereço 2: Rua Desembargador Sales, 624, Parnaíba-PI - Tel.: (086) 88047926

Endereço 3: Avenida Pinheiro Machado, 665 - Bairro Piauí.

Parnaíba - PI. Tel.: (86) 99328002/94337292

Endereço 4: Rua Agrimensor Alprim da Silva Arri, 259 -

Apartamento 03 - Condomínio Rocha Portela, Parnaíba-PI - Tel: (086) 99250460
O trabalho consiste em uma atividade fundamental na vida das pessoas. É através dele que se vê a possibilidade de viver em sociedade, e cada vez mais se verifica a importância que o trabalho assume no cotidiano de cada um. Torna-se relevante, portanto, a realização de diferentes estudos acerca do indivíduo no ambiente de trabalho, o que vem sendo realizado 
com maior frequência atualmente, configurando-se como um meio significante para o entendimento da relação homem- trabalho.

Nesse contexto, entende-se o trabalho como uma atividade através da qual o homem se transforma e é transformado, tendo em vista que todo indivíduo é um ser social, que é determinado historicamente (Carlotto, 2002). Levando em consideração a importância do trabalho para o ser humano, cabe destacar a profissão de professor, já que ultimamente tem sofrido transformações na medida em que novas exigências são impostas ao professor, influenciando diretamente na saúde destes profissionais (Cruz, Lemos, Welter \& Guisso, 2010).

Nesse sentido, uma das consequências diz respeito à Síndrome de burnout, uma vez que esta tem se configurado como frequente no meio docente e tem sido tema de diversas pesquisas na área da educação e saúde (Silva, 2006; Jbeili, 2008; Carlotto, 2002). Sobre isso, Benevides-Pereira (2004) menciona que o burnout ocorre a partir do estresse ocupacional, e seus sintomas envolvem aspectos físicos, comportamentais, psíquicos e defensivos.

Além disso, sua incidência inclui três dimensões: exaustão emocional, despersonalização e falta de realização pessoal no trabalho (Maslach \& Jackson, 1981). No trabalho docente, o burnout acarreta um desgaste emocional que prejudica a relação professoraluno, professor-instituição e principalmente sua saúde (Silva, 2006). No que concerne à relação professoraluno, Carlotto (2002) aponta que é considerada a maior fonte de estresse e, consequentemente, burnout para o professor. Deste modo, a autora aponta que para o professor torna-se difícil conseguir manter um equilíbrio entre trabalho e vida pessoal e, diante dos efeitos da síndrome de burnout, acaba pensando em desistir e abandonar suas funções.

Identificar o nível de predisposição à síndrome de burnout na categoria profissional em questão torna-se relevante na medida em que possibilita uma reflexão acerca da temática e pode servir de subsídios para possíveis intervenções por parte da instituição pesquisada, no que se refere à saúde mental dos seus profissionais, a fim de promover qualidade de vida no trabalho e reabilitação profissional desses sujeitos. Além disso, poderá beneficiar no equilíbrio das atividades, diminuindo os índices de acometimento e prevenindo o agravamento dessa síndrome. Em outras palavras, Da Silva et al. (2014) reforçam essa ideia apontando que é necessária e relevante a realização de pesquisas nacionais que contribuam para o diagnóstico, intervenção e prevenção dessa patologia ocupacional, proporcionando dados que possam promover a articulação de estratégias que viabilizem melhorias, mediante prevenção e intervenções eficazes.

Ressalte-se que a prevenção ao burnout em professores não é uma tarefa somente dos próprios profissionais, mas deve contemplar ações conjuntas entre professores, alunos, instituições de ensino e sociedade (Carlotto \& Palazzo, 2006), a fim de prevenir as consequências provenientes do desenvolvimento da síndrome, como os constantes afastamentos do trabalho, altos índices de absenteísmo, abandono da profissão, problemas no convívio interpessoal com colegas e alunos, baixa produtividade em sala de aula e outras variáveis.

Diante do exposto, o objetivo desta pesquisa foi verificar a predisposição à síndrome de burnout de professores de uma instituição de ensino superior em Parnaíba - Piauí.

\section{Síndrome de burnout}

A palavra "burnout" traduz-se em "perder o fogo", "perder a energia" ou "queimar para fora" (Codo \& Vasques-Menezes, 1999). Diz respeito a um tipo de estresse ocupacional que incide principalmente em profissionais que atuam com qualquer tipo de "cuidado", através de uma relação direta, ininterrupta e emocional com outras pessoas (Tibúrcio \& Moreno, 2009).

É uma síndrome que tem relação direta com o trabalho, uma vez que o trabalhador se sente inútil ao desempenhar suas atividades laborais, isto é, por mais que se esforce para realizar suas tarefas não encontra bem-estar e prazer no trabalho. Assim, diante de um quadro que revela o desânimo profissional e traz consequências para outras esferas da vida, o profissional acaba por pensar em abandonar seu trabalho (Carlotto, 2002).

De acordo com a autora citada anteriormente, a perspectiva social-psicológica de Maslach e colaboradores é a mais aceita ao se conceituar burnout e destaca que essa perspectiva é composta pelas dimensões: exaustão emocional, baixa realização profissional e despersonalização. Para Lima (2009) altos índices desta síndrome são verificados a partir de um nível alto de exaustão emocional e despersonalização, além de nível baixo de falta de realização pessoal.

Sobre isso, Vieira et al. (2006) afirmam que níveis altos de Exaustão estão representados pela fadiga, falta de forças para trabalhar, além da sensação de que há uma exigência para a realização do trabalho que vai além dos próprios limites. Em relação à Realização Profissional, sua falta diz respeito à ausência de perspectivas com relação ao futuro, frustração, sensação de incompetência e fracasso. E, por fim, a Despersonalização se define pelo distanciamento emocional referente ao trabalho e pessoas a quem presta serviço.

Para Benevides-Pereira (2002) os sintomas de burnout são divididos em quatro categorias: físicos - fadiga constante e progressiva, distúrbios do sono, irritabilidade, dores musculares ou osteo-musculares, 
cefaléias, enxaquecas; comportamentais - negligência ou excesso de escrúpulos, irritabilidade, incremento da agressividade, incapacidade para relaxar; psíquicos - falta de atenção, de concentração, alterações de memória, lentificação do pensamento, sentimento de alienação; defensivos - tendência ao isolamento, sentimento de onipotência, perda do interesse pelo trabalho.

Cabe ressaltar que tais sintomas variam de pessoa para pessoa, pois dependem do próprio indivíduo e do ambiente de trabalho. Para Benevides-Pereira (2002) os três primeiros sintomas também estão presentes em casos de estresse, porém os sintomas defensivos ocorrem apenas em casos de burnout. Sobre as causas, a autora pontua que estão relacionadas às características pessoais, a atividade realizada e as variáveis advindas da organização/instituição onde o trabalho é desenvolvido.

Desta forma, verifica-se que a incidência da síndrome diz respeito a um processo desencadeado a partir de vários fatores interligados ao indivíduo e o trabalho, sendo um elemento de grande relevância dentro do contexto da prevenção de riscos laborais e da análise das condições de trabalho, visto que se encontra vinculada a grandes custos organizacionais e pessoais (Da Silva et al.,2014). Sem embargo, atitudes preventivas são necessárias e se configuram como responsabilidade tanto individual quanto das organizações, por um lado cabe ao profissional conhecer os agentes estressores do ambiente de trabalho para que possa ser reduzida sua incidência, por outro lado, para as organizações compete fornecer orientações para seus funcionários com a finalidade de torná-los conhecedores do burnout e suas consequências, e reduzir os aspectos que podem estar favorecendo o adoecimento dos sujeitos, a fim de que assim seja possível tornar o ambiente de trabalho mais saudável e produtivo.

\section{Síndrome de burnout no trabalho docente}

O trabalho de professor, de uma forma geral consiste em uma atividade que está presente há muitos anos, havendo estudos que indicam sua existência desde a Grécia antiga, já considerando sua presença como uma necessidade (Paschoalino, 2008). Antes o professor tinha como responsabilidade auxiliar os jovens cidadãos livres na compreensão do mundo e na argumentação, com o intuito de se emanciparem através do conhecimento, sendo este obtido na escola, que era somente voltado à elite (Paschoalino, 2008).

Mais tarde, na Idade Média, surge a Universidade, “como Instituição que construiu e preservou o patrimônio histórico do Ocidente, inaugurando uma nova forma do conhecimento" (Oliveira, 2006, p. 115), marcando então, como expõe a autora, a história acerca da produção deste. Nesse momento a figura do professor passou a ser relacionada não somente à educação, mas também com um valor voltado ao sacerdócio, sendo necessário à atuação docente o ensinamento de uma doutrina, sendo seu papel ligado também ao poder, podendo julgar, realizar avaliações e excluir os que não demonstrassem obediência aos estudos (Paschoalino, 2008).

Depois, a partir do momento da Revolução Francesa, no século XVIII, o professor passou a ser "visto como uma figura estratégica, o guardião de uma ordem cujo sistema de referência era sagrado e cujas normas econômicas e sociais eram legitimadas pelas normas e valores religiosos." (Carlotto, 2002, p. 22). Verifica-se que a construção do trabalho do professor estava vinculada também à religião.

Referindo-se ao Brasil, é válido destacar que, no século XVI, o ensino formal apresentava como responsável a Companhia de Jesus, cabendo aos jesuítas o papel de educadores (Camilo \& Ribas, 2007). Ainda de acordo com os autores (já se relacionando ao contexto da universidade), os primeiros cursos universitários surgiram no país no século XIX, sendo os cursos de Medicina, Direito e Politécnica organizados de forma independente uns dos outros e com uma orientação profissional voltada à elite.

Mais tarde, no Brasil, o papel do professor (no caso, professor universitário), esteve voltado principalmente a ensinar os alunos (da elite) a serem bons profissionais, assim como ele, sendo convidado a trabalhar na universidade por conta de sua experiência e bom desempenho, não precisando de uma formação específica: "ensinar significava ministrar grandes aulas expositivas e palestras sobre determinado assunto [...]" (Camilo \& Ribas, 2007, p. 4).

Com a realização de algumas exposições acerca da profissão do professor e, mais especificamente, do professor universitário, verifica-se sua relevância na sociedade, entendendo-se que ele está presente no contexto da Universidade, que é considerado o primeiro local de saber universalizante construído no Ocidente, no decorrer de cerca de dois mil anos (Oliveira, 2006).

Hoje, verifica-se que, com frequência, a profissão docente, de uma forma geral, veio sofrendo mudanças, passando por momentos considerados tensos, a fim de que obtivesse uma identidade (Paschoalino, 2008), sendo evidente uma modificação no que diz respeito à exigência de que o professor universitário necessite ter formação específica. Entende-se que, com as grandes transformações ocorridas no contexto social, os educadores passaram a ter mais responsabilidades e maiores exigências em qualquer nível de ensino (Carlotto, 2004). Ainda segundo a autora, para atender as expectativas, a profissão de professor vem, então, se modificando. Nesse sentido, a universidade vem transformando seus currículos, adaptando-se às exigências, com o intuito de que se garanta a inserção dos estudantes no mercado de trabalho (Camilo \& Ribas, 2007). 
Algumas configurações do trabalho docente como as novas tecnologias que além de estimular a construção criativa e capacidade de reflexão, exigem capacitação docente (Camilo \& Ribas, 2007) e a necessidade de participação em comissões, publicação, pesquisa (Garcia \& Benevides-Pereira, 2003) podem conduzir a situações de enriquecimento e motivação para o trabalho. No entanto, podem também ocasionar ou aumentar os estressores relacionados às suas funções ou ao contexto institucional e social onde estas são exercidas (Carlotto, 2004). Entre os diversos fatores causadores do estresse ocupacional do professor, estão: as condições precárias de trabalho, baixa

Tabela 1

Dados sociodemográficos profissional/ocupacional

\begin{tabular}{|c|c|c|c|}
\hline Variável & Categoria/Freq. & Quantidade & $\%$ \\
\hline \multirow[t]{2}{*}{ Sexo } & $\mathrm{M}$ & 49 & 45,8 \\
\hline & $\mathrm{F}$ & 58 & 54,2 \\
\hline \multirow[t]{5}{*}{ Idade } & $26-30$ & 5 & 4,7 \\
\hline & $31-35$ & 54 & 50,5 \\
\hline & $36-40$ & 30 & 28 \\
\hline & $41-45$ & 10 & 9,4 \\
\hline & Acima de 46 anos & 8 & 7,4 \\
\hline \multirow[t]{5}{*}{ Estado Civil } & Solteiro & 29 & 27,1 \\
\hline & Casado & 69 & 64,4 \\
\hline & Divorciado & 6 & 5,5 \\
\hline & Viúvo & 1 & 1,2 \\
\hline & Outros & 2 & 1,8 \\
\hline \multirow[t]{3}{*}{ Escolaridade } & Pós-graduado & 8 & 7,4 \\
\hline & Mestrado & 63 & 59 \\
\hline & Doutorado & 36 & 33,6 \\
\hline \multirow[t]{11}{*}{ Curso } & Administração & 6 & 5,6 \\
\hline & Biologia & 13 & 12,1 \\
\hline & Biomedicina & 14 & 13 \\
\hline & Ciências Contábeis & 7 & 6,5 \\
\hline & Ciências Econômicas & 7 & 6,5 \\
\hline & Engenharia de Pesca & 11 & 10,2 \\
\hline & Fisioterapia & 12 & 11,2 \\
\hline & Matemática & 10 & 9,4 \\
\hline & Pedagogia & 8 & 7,4 \\
\hline & Psicologia & 10 & 9,4 \\
\hline & Turismo & 9 & 8,4 \\
\hline \multirow[t]{2}{*}{ Projeto de Pesquisa } & $\operatorname{Sim}$ & 58 & 55,8 \\
\hline & Não & 46 & 44,2 \\
\hline \multirow[t]{2}{*}{ Projeto de Extensão } & Sim & 54 & 51,4 \\
\hline & Não & 51 & 48,6 \\
\hline \multirow[t]{4}{*}{ Situação de Trabalho } & Concursado & 105 & 98,2 \\
\hline & Substituto & 0 & 0 \\
\hline & Prestador de Serviços & 0 & 0 \\
\hline & Outros & 2 & 1,8 \\
\hline \multicolumn{4}{|c|}{ Tempo de atuação na universidade (meses) } \\
\hline & $0-150$ & 101 & 94,6 \\
\hline & $151-250$ & 4 & 3,6 \\
\hline & Acima de 251 & 2 & 1,8 \\
\hline
\end{tabular}

Fonte: Dados da pesquisa, Parnaíba: 2011 remuneração, a longa jornada de trabalho, a pouca ou quase nenhuma oportunidade de qualificação e a falta de reconhecimento e valorização (Monteiro, 2010).

Professores quando predispostos a síndrome de burnout, apresentam características de grande exaustão física e emocional. Garcia e BenevidesPereira (2003) afirmam que, em consequência das frustrações causadas por esse fenômeno, os sentimentos de inferioridade, tristeza, ansiedade surgem como respostas psicológicas, assim como se desenvolvem problemas psicossomáticos, como insônia, úlceras, dores de cabeça e hipertensão, bem como o consumo abusivo de álcool e medicamentos.
Biomedicina $\quad 14$

Ciencias Contábeis

Engenharia de Pesca 11

Concursado 105 
Carlotto (2002) acredita que a relação entre o burnout e os aspectos profissionais pode provocar nos professores a diminuição nas suas atividades de planejamento, pouco entusiasmo e criatividade no trabalho, bem como o sentimento de frustração pelos problemas ocorridos em sala de aula ou pela falta de progresso de seus alunos, desenvolvendo distanciamento com relação a estes.

Ainda de acordo com Carlotto (2004), as consequências do burnout em professores, as quais se manifestam no campo pessoal e profissional, refletem na instituição de ensino e na relação com os alunos, interferindo assim na obtenção dos objetivos pedagógicos. Para Carlotto e Palazzo (2006), os profissionais que apresentam essa síndrome podem ser levados a um processo de alienação, desumanização e apatia, ocasionando problemas de saúde, absenteísmo e intenção de abandonar a profissão.

Portanto, entende-se que sendo a figura do professor universitário caracterizada "pela diversidade, pela pluralidade de opções, caminhos, alternativas, interesses e tensões." (Carlotto, 2004, p. 147) é relevante a realização de estudos relacionados a essa categoria profissional.

\section{Método}

\section{Amostra}

A amostra do tipo estratificada proporcional constituiu-se de 107 professores de uma universidade pública da cidade de Parnaíba, contando com docentes de todos os cursos: Administração, Biologia, Biomedicina, Ciências Contábeis, Ciências Econômicas, Engenharia de Pesca, Fisioterapia, Matemática, Pedagogia, Psicologia e Turismo.

A tabela 1 mostra o total de professores, a porcentagem por curso e suas características sociodemográficas:

O questionário foi aplicado em 49 professores e 58 professoras. Quanto aos dados acadêmicos, foi perguntado aos professores o seu grau de formação; $7,4 \%$ dos pesquisados afirmaram ter apenas pósgraduação na sua área de atuação, 59\% possuem mestrado e $33,6 \%$ possuem formação em doutorado. Em relação à realização de projetos de pesquisa no referido período, pouco mais da metade dos professores $(55,8 \%)$ respondeu que realizam projetos com os alunos, e os demais $(44,2 \%)$ não realizam essa atividade. No que se refere à execução de projetos de extensão, $51,4 \%$ disseram que participam de projetos, já os 48,6\% restantes revelaram não participar.

\section{Instrumentos de coleta de dados}

Para a coleta de dados, utilizou-se como instrumento um questionário sociodemográfico, contendo questões pessoais referentes à idade, sexo, estado civil, escolaridade, e profissional/ocupacional, com questões como: tempo de atuação na universidade pesquisada, curso em que atua e situação de trabalho (concursado, substituto, prestador de serviço ou outro). Esses dados foram coletados com o objetivo de conhecer o perfil dos professores e obter dados relativos à atuação destes no Campus estudado.

Foi empregado também o Maslach Burnout Inventory (MBI - ED, 1986), elaborado por Maslach e Jackson (1986). Para este estudo, foi utilizada uma versão exclusiva para profissionais da educação, adaptada no Brasil por Carlotto e Câmara (2007) segundo Nunes, Consulin, Pereira \& Mariotto (2011). Ressalta-se que se trata de um instrumento de ampla utilização em pesquisas que se propõem a avaliar a predisposição ao burnout (Cotrim \& Wagner, 2011; Mallmann, Palazzo, Carlotto \& Aerts, 2009; Silva, 2006).

$\mathrm{O}$ MBI é composto por 22 questões relativas às três dimensões já citadas anteriormente: Exaustão (9 itens), Realização Profissional (8 itens) e Despersonalização (5 itens), sendo considerado que altos índices na primeira e terceira dimensões e baixos na segunda refletem predisposição à síndrome de burnout. A frequência das respostas é avaliada mediante pontuação que varia de 0 a $6(0=$ nunca/ $1=$ uma vez ao ano ou menos/ $2=$ uma vez ao mês ou menos/ $3=$ algumas vezes ao mês/ $4=$ uma vez por semana/ $5=$ algumas vezes por semana/ $6=$ Todos os dias).

\section{Procedimentos}

Após a aprovação do CEP para a realização da pesquisa, entrou-se em contato com a direção da instituição, solicitando a realização da pesquisa e, em seguida, com os participantes, para os quais o Termo de Consentimento Livre e Esclarecido (TCLE) foi apresentado, a partir disso, reforçava-se a ética, destacando sua participação voluntária e o sigilo quanto aos dados coletados. Ao aceitar participar da pesquisa, os professores assinavam o TCLE e garantiam sua colaboração na pesquisa. Em seguida, era aplicado o questionário sociodemográfico e profissional/ocupacional e o Maslach Burnout Inventory (MBI).

\section{Análise dos dados}

Quanto à análise dos dados, esta foi do tipo quantitativo, tendo em vista que se pretendeu mensurar as características da amostra de professores e à incidência a síndrome de burnout.

A análise dos dados foi realizada através do software estatístico SPSS, versão 18.0. Primeiro foi realizada uma análise de frequência dos dados sociodemográficos profissionais/ocupacionais, com a finalidade de obter dados que caracterizam a amostra estudada. Com o objetivo de verificar a predisposição à síndrome de burnout, inicialmente utilizou-se a Análise Fatorial (AF), que possibilitou a identificação das dimensões do MBI e que trata-se de uma técnica 
estatística que identifica fatores capazes de explicar a relação entre diversas variáveis (Bezerra, 2007).

Como método de extração, foi realizada a Análise de Componentes Principais (ACP) e o tipo de análise efetuado foi o R-mode factor analysis, sendo que o critério do autovalor (eigenvalue) foi utilizado para selecionar o número de fatores; o tipo de rotação utilizado foi a varimax, a fim de aumentar o poder de explicação da Análise Fatorial.

Também foi empregado o Alfa de Cronbach, com o intuito de averiguar a consistência interna dos fatores. Considerou-se que, para a consistência interna ser satisfatória, o Alfa de Cronbach precisa estar entre os valores 0,71 e 0,90 (Maslach \& Jackson, 1981). Também foi empregado o teste de Kaiser-MeyerOlkin (KMO) e o Teste de Esfericidade de Bartlett, o primeiro para confirmar se o número de fatores encontrado consegue explicar os dados obtidos, e o segundo para verificar se há correlação suficiente entre as variáveis, isto é, ambos com o objetivo de verificar se para as variáveis selecionadas a AF tem validade.

Além disso, foi considerada a média de cada dimensão e analisada a partir da escala do tipo Likert, presente no Maslach burnout Inventory (MBI - ED), de 1986, variando de 0 (nunca) a 6 (todos os dias). Para finalizar, com o objetivo de avaliar a frequência na amostra pesquisada à predisposição à síndrome de burnout, também foi feita uma análise de frequência, variando entre baixa, média e alta, associando as suas respectivas porcentagens.

Ressalta-se que, para avaliar a tendência à predisposição a síndrome, consideraram-se altos índices de Exaustão e Despersonalização e baixos índices de Realização Profissional.

\section{Resultados}

Foi realizada, inicialmente, a Análise Fatorial (AF), que consiste em uma técnica estatística que busca agrupar variáveis em dimensões de variabilidade comum, com cada dimensão sendo chamada de fator (Bezerra, 2007). Com isso, reduziu-se as variáveis do MBI em fatores que pudessem explicar a relação entre elas.

Através do teste de Kaiser-Meyer-Olkin (KMO) foi encontrado um valor de 0,782 , sendo considerado um alto grau de explicação dos dados. O Teste de Esfericidade de Bartlett indicou uma relação suficiente entre os indicadores para que se aplicasse a AF, devido à significância não ter ultrapassado 0,05 .

$\mathrm{Na}$ pesquisa realizada, foram encontrados três fatores, que são a Exaustão (fator 1), Realização Profissional (fator 2) e Despersonalização (fator 3 ), coincidindo com os três fatores propostos por Maslach e Jackson (1981). Obteve-se, neste estudo, uma variância total de $39,38 \%$, o que, com essa porcentagem, evidencia-se um grau satisfatório de relação entre as variáveis.

É importante destacar que o primeiro fator (Exaustão) apresentou variância de aproximadamente 23,85\%; o segundo (Realização Profissional), de 10,12\%; e o terceiro (Despersonalização), de 5,39\%, evidenciando que o primeiro teve um grau de explicação maior que os outros.

Para avaliar a consistência interna dos fatores obtidos, utilizou-se a análise do Alpha de Cronbach. O Alpha de Cronbach foi proposto por L. J. Cronbach e é considerado por muitos pesquisadores "o índice universalmente aconselhável para o estudo métrico de uma escala (qualquer que sejam as suas características) como tendem a percebê-lo como fornecendo 'estimativas fiáveis' da 'fiabilidade de uma escala"" (Maroco \& Garcia-Marques, 2006, p. 66). O Alpha da dimensão Exaustão foi 0,87; da Realização Profissional, 0,79; e da Despersonalização, 0,63 . Verifica-se, desse modo, uma consistência interna considerada alta de cada fator do instrumento aplicado, visto que essas dimensões medem $87 \%$, $79 \%$ e $63 \%$, respectivamente, do impacto real das variáveis.

Com relação às dimensões do burnout, foram obtidas as seguintes médias: 2,47 na dimensão Exaustão, sugerindo a ocorrência de esgotamento uma vez ao mês ou menos; 4,56 na Realização Profissional, indicando haver sensação de competência uma vez por semana; 0,85 na Despersonalização, correspondendo a um distanciamento do trabalho uma vez ao ano ou menos.

Assim, a partir da correlação entre a escala likert de 0 a 6 do MBI e as médias obtidas em cada dimensão, os resultados apontaram índice baixo para as dimensões Exaustão e Despersonalização 2,47 e 0,85 , respectivamente, e alto para a dimensão Realização Profissional $(4,56)$.

Tabela 2

Teste KMO e Teste de Bartlett do MBI-ED

\begin{tabular}{lcc}
\hline TESTE KMO &, 782 \\
& & \\
\hline Teste de Esfericidade de Bartlett & Approx. Chi- Square & 845,056 \\
& DF & 231 \\
& Significância &, 000 \\
\hline
\end{tabular}

Fonte: Dados da pesquisa, Parnaíba: 2011. 
Tabela 3

Matriz estrutural dos fatores da sindrome de burnout

\begin{tabular}{lcccc}
\hline & Cargas fatoriais & & \\
& Variáveis & Fator 1 & Fator 2 & Fator 3 \\
\hline E1 & 0,774 & - & - \\
E2 & 0,731 & - & - \\
E3 & 0,705 & - & - \\
E6 & 0,545 & - & - \\
E8 & 0,870 & - & - \\
E14 & 0,715 & - & - \\
E16 & 0,633 & - & - \\
RP4 & - & 0,679 & - \\
RP7 & - & 0,638 & - \\
RP9 & - & 0,525 & - \\
RP17 & - & 0,544 & - \\
RP18 & - & 0,703 & - \\
RP21 & - & 0,634 & - \\
D5 & - & - & 0,388 \\
D10 & - & - & 0,768 \\
D11 & - & - & 0,639 \\
Porcentagem de variância explicada & $23,85 \%$ & $10,12 \%$ & $5,39 \%$
\end{tabular}

Fonte: Dados da pesquisa, Parnaíba: 2011.

Com relação à frequência dos participantes com predisposição à síndrome, verificou-se que 34,5\% dos professores apresenta nível baixo de Exaustão; em contrapartida, $32,75 \%$ apresentaram níveis de médio a alto. A respeito da Realização Profissional, $35,4 \%$ apontaram um nível baixo; 32,7\%, alto; e $31,9 \%$, médio. Para a Despersonalização, 38,9\% demonstraram ter baixo índice; 31,9\%, médio; e 29,2\%, alto. Tais dados são descritos na Tabela 5:

Através desses dados, verifica-se uma porcentagem baixa nas dimensões Exaustão e Despersonalização e altos níveis de Realização Profissional. Entretanto, na dimensão Exaustão observou-se a existência de esgotamento, já que alguns participantes responderam na média entre "uma vez ao mês ou menos" e "algumas vezes ao mês", evidenciando a necessidade de considerar os dados obtidos como indícios de predisposição à síndrome.

\section{Discussão e Considerações Finais}

Os dados obtidos a partir da Análise Fatorial permitiram verificar que o Alpha de Cronbach para os fatores encontrados apresentou consistência interna alta, possibilitando maior confiabilidade. De modo similar, o grau de explicação também pode ser visualizado através dos valores obtidos pelo KaiserMeyer-Olkin (KMO) e pelo Teste de Esfericidade de Bartlett, configurando alta consistência e explicação para os mesmos.

Há indicativos de síndrome de burnout quando são obtidos escores altos nas dimensões Exaustão e Despersonalização e baixos na dimensão Realização Profissional (Campos, 2005). Dessa forma, no que se refere às três dimensões encontradas a partir da análise fatorial realizada no MBI, obteve-se que, apesar de indicarem baixa predisposição à síndrome, merecem atenção em virtude da Exaustão ter apresentado um índice considerável de esgotamento, já que os indivíduos se apresentaram na média entre "uma vez ao mês ou menos" e "algumas vezes ao mês". Fascina, Guimarães, Hidaka, Mekler e Rezende (2007) afirmam que baixos escores nas dimensões Exaustão e Despersonalização e altos escores na dimensão Realização Profissional evidenciam baixo grau de burnout, não descartando, portanto, a predisposição.

Sobre a dimensão Exaustão Emocional, quando há baixos índices, o senso de controle e de compromisso,

Tabela 4

Média e desvio padrão das dimensões da síndrome de burnout.

\begin{tabular}{cccc|}
\hline Dimensões & Exaustão & Realização Profissional & Despersonalização \\
\hline Média & 2,4695 & 4,5605 & 0,8515 \\
Desvio Padrão & 1,33409 & 1,04249 & 1,02498 \\
\hline
\end{tabular}

Fonte: Dados da pesquisa, Parnaíba: 2011. 
Tabela 5

Frequência da predisposição dos participantes à síndrome de burnout

\begin{tabular}{|c|c|c|c|c|c|}
\hline & & $(\%)$ & Média (\%) & Alta & Total \\
\hline Exaustão & 39 & $(34,5)$ & $37 \quad(32,75)$ & $37 \quad(32,75)$ & 113 \\
\hline Realização Profissional & 40 & $(35,4)$ & $(31,9)$ & $(32,7)$ & 113 \\
\hline Despersonalização & 44 & $(38,9)$ & $(31,9)$ & $(29,2)$ & 113 \\
\hline
\end{tabular}

Fonte: Dados da pesquisa, Parnaíba: 2011

assim como o desafio orientado, apresentam-se como mais potentes (Campos, 2005). Isso mostra que, com a maioria dos professores, não ficou evidente uma caracterização prevalente de esgotamento em seu ambiente de trabalho.

Entretanto, vale ressaltar que uma quantidade significativa também apresentou frequências média e alta no que diz respeito a esse fator. Isso pode ocorrer devido ao fato de a maioria dos participantes realizarem várias atividades ao mesmo tempo, indo além de seu trabalho curricular em sala de aula, com uma sobrecarga em seu trabalho. Garcia e BenevidesPereira (2003) citam, por exemplo, a necessidade de leituras para preparação de aulas como uma atividade a mais que o professor necessita fazer.

A partir dos resultados obtidos em relação ao fator Exaustão, evidencia-se tanto uma frequência mais baixa (o que foi apontado pela maioria), quanto uma frequência maior (média e alta), sendo possível destacar o que Carlotto (2004) afirma sobre a nova configuração do trabalho de professor, que pode tanto proporcionar situações de desenvolvimento e motivação no trabalho, quanto gerar e aumentar aspectos relacionados ao estresse nesse contexto.

No que se refere à Realização Profissional, os resultados indicaram uma satisfação maior dos docentes, o que pode se destacar que, apesar das várias atividades desempenhadas, não se indicou uma falta de realização expressiva por isso, não sendo apontada uma presença tão frequente de problemas em suas relações interpessoais no ambiente de trabalho. Também é preciso considerar nesse fator as outras frequências, que indicam menor realização profissional, sendo esse um aspecto que autores que se dedicam nos estudos à síndrome de burnout ressaltam em relação à atividade docente que, por estar em um ambiente que necessita que os professores tenham contato direto com outras pessoas, essa situação pode facilitar sua predisposição à síndrome (Garcia \& Benevides-Pereira, 2003).

Em relação à dimensão Despersonalização, é preciso que também haja cuidado ao considerála, visto que ela expressa uma forma de defesa do trabalhador, caracterizando-se "por tratar os clientes, colegas e a organização como objetos" (Carlotto, 2002, p. 23). Desse modo, referindo-se ao trabalho de professor universitário que, de acordo com a autora citada a pouco, precisa se deparar com muitos papéis (auxiliando o aluno, por exemplo) e, ao mesmo tempo manter o equilíbrio da situação, é relevante haver uma atenção significativa a essa categoria profissional, já que, devido a essas situações com as quais ele se depara, pode ser facilitado o aparecimento da despersonalização. Com os participantes deste estudo, não foi evidente a presença dessa característica, entretanto, pelo fato de terem sido indicadas algumas frequências nesse fator, também é relevante uma atenção especial em relação a esse aspecto.

Ainda sobre a dimensão Despersonalização, também é válido verificar que, quanto ao resultado do Alpha de Cronbach, que foi de 0,63, apesar de haver uma consistência interna considerada alta, ela se apresentou em um valor menor (considerando-se as outras dimensões), notando-se que isso pode ter ocorrido pelo fato de que ela se trata de um aspecto que tende a não estar presente no início, como pesquisas apontam, visto que, em profissões que lidam constantemente com outras pessoas, oferecendo ajuda, os indivíduos apresentam maiores dificuldades em reconhecer essa característica, por conta de sua imagem como profissional (Lima et al., 2009).

Diante dos resultados obtidos, embora não tendo sido evidente a predisposição dos participantes à síndrome de burnout, é importante que se leve em consideração os fatores presentes nela, visto que uma porcentagem significativa de professores respondeu de acordo com as três dimensões: tanto frequências médias e altas para Exaustão e Despersonalização, quanto frequências baixas para Realização Profissional.

A preocupação com os professores pesquisados se torna importante, tanto por conta dos resultados obtidos, quanto pelo fato de pesquisas apontarem que o trabalho de professor precisa receber atenção no que se refere à síndrome de burnout, sendo "um problema social de extrema relevância" (Carlotto, 2004, p. 148), que pode gerar consequências negativas, como o que Carlotto (2002) afirma, ressaltando que as implicações da síndrome de burnout em professores se refletem na organização escolar e na relação com os alunos (por exemplo) e, no que se refere ao contexto universitário, verifica-se que o problema pode se refletir então na organização de atividades no âmbito acadêmico.

A partir dos resultados obtidos, a preocupação com os professores pesquisados se torna justificável, pois, embora a maioria dos resultados não tenha apontado predisposição, percebe-se que alguns participantes apresentam médios e altos índices de exaustão, 
tornando-se necessária a realização de mais estudos voltados aos professores universitários sobre o tema, a fim de que proporcione outras contribuições a essa categoria profissional.

Portanto, com os resultados desta pesquisa, percebeu-se que a realização da Análise Fatorial proporcionou conhecimento acerca dos professores pesquisados no que se refere ao MBI - ED (Maslach Burnout Inventory), permitindo que se realizasse um estudo avaliativo da predisposição ao burnout nos mesmos, que consistiu no objetivo do trabalho, verificando-seastrêsdimensõesencontradas(Exaustão; Realização Profissional; Despersonalização). Além disso, os dados sociodemográficos e profissionais/ ocupacionais obtidos possibilitaram um entendimento maior acerca dos sujeitos pesquisados, contribuindo para a verificação de seu contexto na vida pessoal e no ambiente de trabalho.

Assim, foi possível observar o que a literatura estudada expõe sobre o trabalho docente, como por exemplo, o fato de que os professores da pesquisa realizam atividades que vão além da sala de aula, que grande parte participa tanto de atividades de pesquisa quanto de extensão, além de que apresentam uma formação além da graduação.

Desse modo, entendeu-se que, apesar das diferentes atividades realizadas pelos professores (que proporcionam, então, maior contato direto com outras pessoas, o que pode facilitar a predisposição), podese observar que não foi indicada uma predisposição à síndrome (considerando a maioria dos resultados), embora seja possível observar indícios em algumas respostas no que diz respeito às três dimensões encontradas. Baseando-se nisso, é importante que estudos como esse sejam replicados, nesse e em outros contextos, a fim de que se busque identificar (para prevenir) possível predisposição à síndrome em uma categoria que apresenta peculiaridades e está, por vezes, inserida em condições de trabalho que geram vulnerabilidade e adoecimento tanto físico quanto mental. Nesse sentido, apoia-se em Batista et al. (2013) e Da Silva (2014) e sugere-se que é importante a adoção de estratégias organizacionais e individuais no contexto universitário, com vistas a combater a síndrome e/ou minimizar os seus efeitos sobre o trabalhador e proporcionar uma melhoria na qualidade vida no trabalho, e em consequência, promover uma educação de qualidade.

\section{Referências}

Batista, J. B. V.; Batista, P. S. S.; Barros, E. O.; Lopes, F. S. R.; Medeiros, G. B. P. \&Morais, J. M. D. Síndrome de burnout: compreensão de profissionais de enfermagem que atuam no contexto hospitalar. Revista de Enfermagem UFPE on line, Recife, 7 (2), p.553-61.

Benevides-Pereira, A. M. T. (2002). Burnout, por quê? Uma introdução. In: Benevides-Pereira, A. M. T. (org.) Burnout: quando o trabalho ameaça o bem-estar do trabalhador. São Paulo: Casa do
Psicólogo, pp. 13-20.

Benevides- Pereira, A. M. T. (2004). A síndrome de burnout. In: Conferência proferida no I Congresso Internacional sobre Saúde Mental no Trabalho, Goiânia, p. 36- 51.

Bezerra, F. A. (2007). Análise Fatorial. Em: Paulo, E.; Filho, J. M. D. F.; Corrar, L. J. (2007). Análise Multivariada para os cursos de Administração, Ciências Contábeis e Economia. Editora Atlas.

Camilo, M. \& Ribas, K. M. F. (2007). Formação docente: professor universitário na atualidade. Revista Eletrônica Lato Sensu, 2 (1), p. 1- 21.

Campos, R. G. (2005). Burnout: uma revisão integrativa na enfermagem oncológica. Dissertação de Pós- graduação, Departamento de Enfermagem Geral e Especializada da Escola de Enfermagem de Ribeirão Preto, Universidade de São Paulo, São Paulo, SP.

Carlotto, M. S. (2002). A síndrome de Burnout e o trabalho docente. Psicologia em Estudo, 7.

Carlotto, M. S. (2004). Síndrome de burnout e características de cargo em professores universitários. Revista Psicologia: Organizações e Trabalho, 4.

Carlotto, M. S. \& Câmara, S. G. (2007). Propriedades psicométricas do Maslach Burnout Inventory em uma amostra multifuncional. Estudos em psicologia, 24 (3).

Carlotto, M. S. \& Palazzo, L. S. (2006). Síndrome de burnout e fatores associados: um estudo epidemiológico com professores. Caderno de Saúde Pública, Rio de Janeiro, p.1017-1026.

Codo, W \& Vasques-Menezes, I. (1999). O que é burnout? In : Codo, Wanderley (Coord.). Educação, Carinho e Trabalho. Petrópolis, Vozes, p. 237-254.

Cotrim, P. S. \& Wagner, L. C. ( 2011). Prevalência da síndrome de Burnout em professores de uma instituição de ensino superior. Ciência em Movimento, XIV (28), p. 61-70.

Cruz, R. M.; Lemos, J. C.; Welter, M. M. \& Guisso, L. (2010). Saúde docente, condições e carga de trabalho. Revista Electrónica de Investigación y Docencia (REID), 4, p.147-160.

Da Silva, L.; Gil-Monte, P. R.; Fátima, R. \& Bovi, G. M. (2014). Prevalência da síndrome de burnout em uma amostra de professores universitários brasileiros. Psicologia: Reflexão e Crítica, 26 (4), in press.

Fascina, L. P.; Guimarães, C. P. A.; Hidaka, K. S.; Mekler, P. L. \& Rezende, F. (2007). Avaliação do nível da Síndrome de Burnout na equipe de enfermagem da UTI- adulto. P. 1-28. Recuperado em 06 dez., 2011, de http:/www.psicocare.net/psicologia/arquivos/ sindrome_burnout.pdf

Garcia, L. P. \& Benevides-Pereira, A. M. T. (2003). Investigando o burnout em professores universitários. Revista Eletrônica InterAção Psy, 1.

Jbeili. C. (2008). Burnout em Professores: Identificação, tratamento e prevenção - Cartilha informativa de prevenção à Síndrome de burnout em professores.

Lima, C. F.; Oliveira, J. A. de; Silva, E. S. da; Emerito, A. P.; Lima, F. D. M.; Souza, R. K. S. de (2009). Avaliação Psicométrica do Maslach Burnout Inventory em Profissionais de Enfermagem. In: II Encontro de Gestão de Pessoas e Relações de Trabalho, Curitiba.

Lima, C. F. (2009). Síndrome de Burnout e Autoeficácia: Um estudo com profissionais de enfermagem de hospitais privados de Natal/RN. Dissertação (Mestrado) - Departamento de Ciências Administrativas, Universidade Federal do Rio Grande do Norte, Natal, RN.

Mallmann, C. S.; Palazzo, L. S.; Carlotto, M. S. \& Aerts, D. R. G. de C. (2009). Fatores associados à síndrome de burnout em funcionários públicos municipais. Psicologia: Teoria e Prática, 11 (2), p. 69-82.

Maroco, J. \& Garcia-Marques, T. (2006). Qual a fiabilidade do alfa de Cronbach? Questões antigas e soluções modernas? Laboratório de Psicologia, 4.

Martínez, J. C. A. (1997). Aspectos Epidemiológicos del Síndrome de Burnout en Personal Sanitario. Revista Espanhola de Salud Pública, 71, p. 293-303.

Maslach, C.; Jackson, S. E. (1981). The measurement of experienced burnout. Journal of Occupational Behaviour, 2. 
Monteiro, V. C. T. (2010). O trabalho docente e a síndrome de burnout. Encontro de Pesquisa em Educação em Alagoas. Recuperado em 30 mar., 2012, de http://dmd2.webfactional.com/ media/anais/O-TRABALHO-DOCENTE-E-A-SINDRO ME-DEBURNOUT.pdf

Nunes, M. F.; Consulin, E. G.; Pereira, M. A. \& Mariotto, R. M. M. (2011). Aplicação do Maslach Burnout Inventory em funcionárias de uma creche de Curitiba-PR. In: X Congresso Nacional de Psicologia Escolar e Educacional. Maringá, Universidade Federal de Maringá. Recuperado em 21 mai., 2014, de www.abrapee.psc.br/xconpe/trabalhos/1/59.pdf

Oliveira, T. (2006). Universidades Medievais: uma história e uma memória educacional. In: VI Congresso Luso-Brasileiro de História da Educação. Programação e Resumos do VI Congresso Luso-Brasileiro de História da Educação. Uberlândia : Gráfica da UFU, p. 1822 - 1834. Recuperado em 24 jan., 2012, de http://www. faced.ufu.br/colubhe06/anais/arquivos/164TerezinhaOliveira.pdf

Paschoalino, J. B. de Q. (2008). A complexidade do trabalho docente na atualidade. In: $1^{\circ}$ SENEPT, Seminário Nacional de Educação Profissional e Tecnológica, Belo Horizonte, p. 1 - 11. Recuperado em 24, jan. 2012, de http://www.senept. cefetmg.br/galerias/Arquivos_senept/anais/quarta_tema6/ QuartaTema6Artigo2.pdf

Silva, M. E. P. (2006). Burnout: por que sofrem os professores? Estudos e Pesquisas em Psicologia, 6 (1). UERJ, RJ.

Tibúrcio, A.; Moreno, C. R. C. (2009). Síndrome de Burnout em professores do ensino médio de escolas pertencentes à gerência regional de educação e inovação (GEREI) do município de Tubarão (SC). Revista de Gestão Integrada em Saúde do Trabalho e Meio Ambiente, 4

Vieira, I.; Ramos, A.; Martins, D.; Bucasio, E.; BenevidesPereira, A. M.; Figueira, I.; Jardim, S. (2006). Burnout na clínica psiquiátrica: relato de um caso. Revista de Psiquiatria do Rio Grande do Sul, 28.

Sobre os autores:

Maria Fabiana Machado da Silva - Graduanda do curso de Psicologia da Universidade Federal do Piauí Campus Universitário de Parnaíba-PI.

E-mail: bianasilva22@hotmail.com

Lauriane Maria dos Santos Teles - Graduanda do curso de Psicologia da Universidade Federal do Piauí Campus Universitário de Parnaíba-PI.

E-mail: laurianeteles@hotmail.com

Savanna de Brito Ximenes Aragão - Graduanda do curso de Psicologia da Universidade Federal do Piauí Campus Universitário de Parnaíba-PI.

E-mail: savannaximenes@hotmail.com

Carla Fernanda de Lima Santiago da Silva - Professora Mestre do curso de Psicologia da Universidade Federal do Piauí - Campus Universitário de Parnaíba-PI.

E-mail: carla.ufpi@yahoo.com.br 